\title{
Supplementary Materials for: \\ Evaluating the Effects of Missing Values and Mixed Data Types on Social Sequence Clustering Using t-SNE Visualization
}

\author{
ALINA LAZAR, Youngstown State University \\ LING JIN, C. ANNA SPURLOCK, KESHENG WU, ALEX SIM, and ANNIKA TODD, \\ Lawrence Berkeley National Laboratory
}

\section{A SUPPLEMENTARY TABLE}

Table A.1. Performance of the Four-Cluster Solution of $D_{\text {combined }}$ on Its Contributing Domains ( $D_{\text {binary }}$ and $D_{\text {nominal }}$ ) Under Different Missing Value Treatments

\begin{tabular}{lcccc}
\hline $\begin{array}{l}\text { Contributing } \\
\text { Domains }\end{array}$ & $\begin{array}{l}\text { With Gaps } \\
\text { NA Cost = 0 }\end{array}$ & $\begin{array}{l}\text { With Gaps } \\
\text { NA Cost = 2 }\end{array}$ & $\begin{array}{l}\text { No Gaps } \\
\text { NA Cost = 0 }\end{array}$ & $\begin{array}{c}\text { No Gaps } \\
\text { NA Cost = 2 }\end{array}$ \\
\hline \multicolumn{5}{c}{ Point Biserial Correlation } \\
$D_{\text {binary }}$ & 0.62 & 0.57 & 0.73 & 0.62 \\
$D_{\text {nominal }}$ & 0.03 & 0.39 & -0.05 & 0.21 \\
& \multicolumn{4}{c}{ Average Silhouette Width } \\
$D_{\text {binary }}$ & 0.47 & 0.27 & 0.55 & 0.35 \\
$D_{\text {nominal }}$ & -0.03 & 0.07 & -0.05 & 0.00 \\
\hline
\end{tabular}

\section{B SUPPLEMENTARY FIGURES}

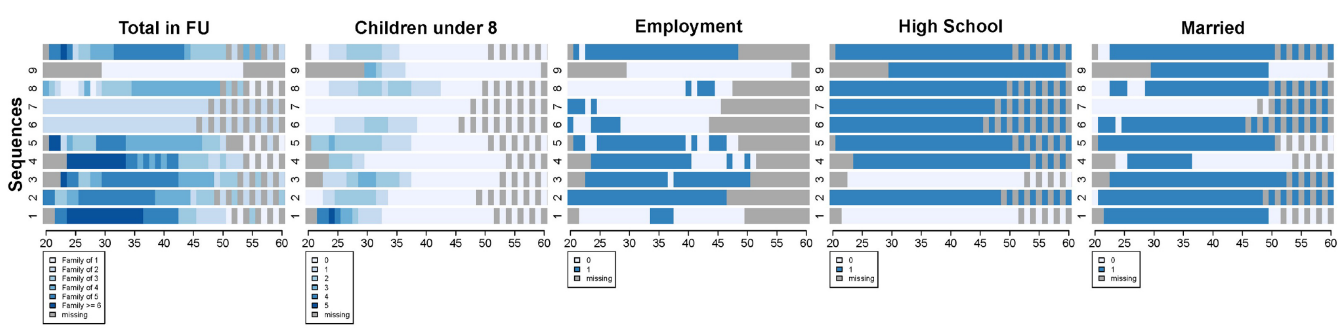

Fig. B.1. Sample individual sequence plots to illustrate the missing patterns in the PSID dataset. Variables are family size ("Total FU"), number of children under 8 ("Children under 8"), employment status ("Employment"), high school degree ("High School”), and marriage status ("Married”).

(c) 2019 Association for Computing Machinery.

1936-1955/2019/03-ART7 \$15.00

https://doi.org/10.1145/3301294 

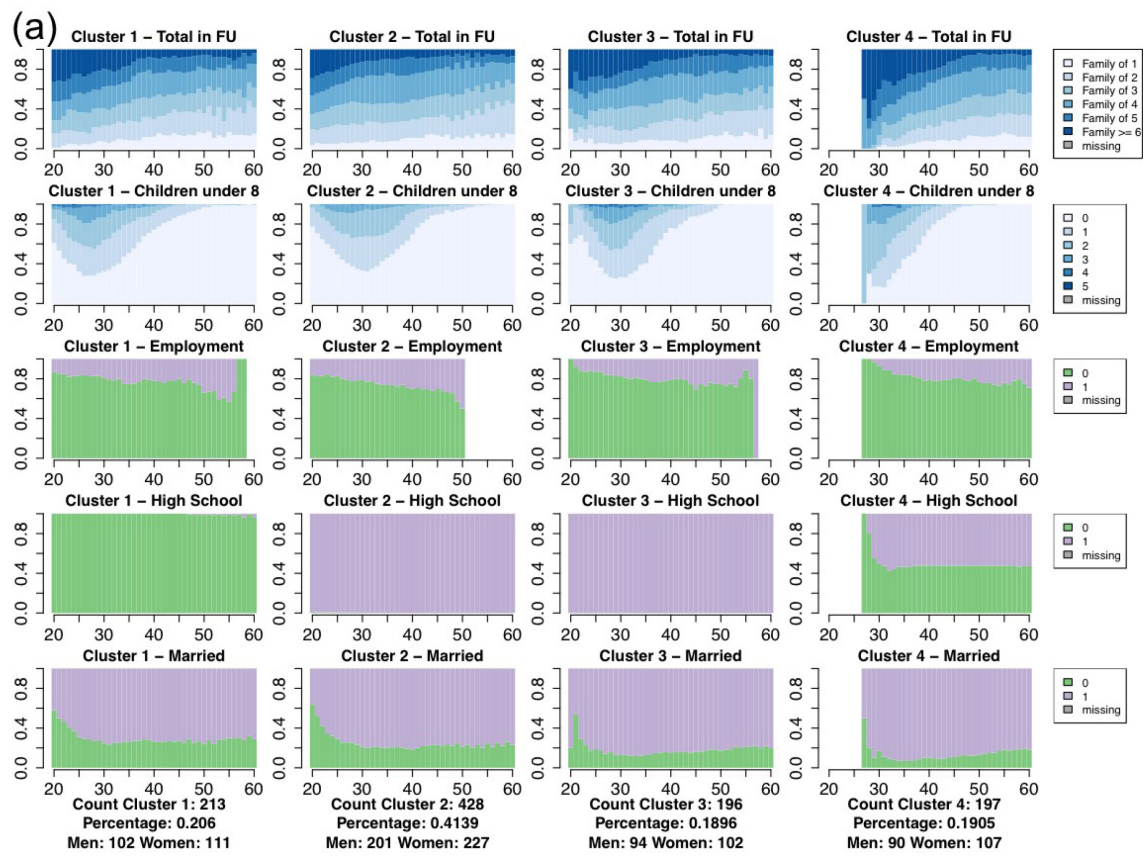

(b) Cluster 1 - Total in FU
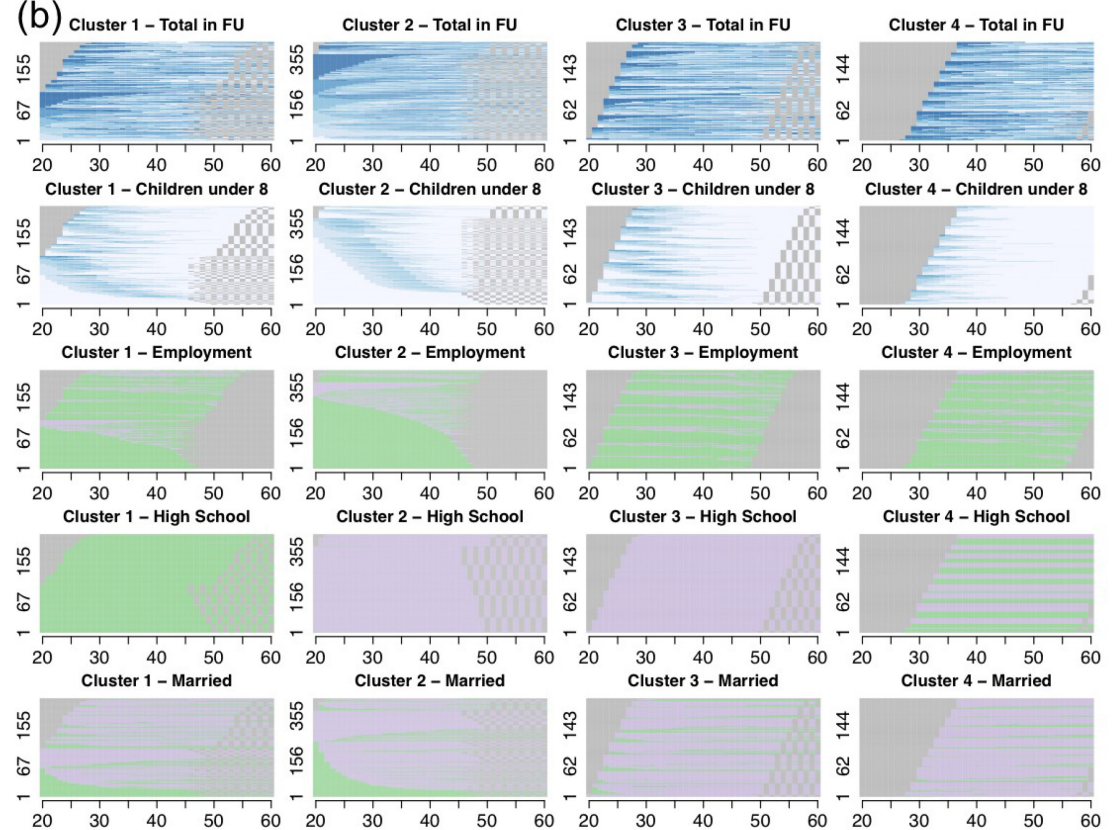

Fig. B.2. Cluster solutions for the combined domain with survey gaps and NA cost $=2$. (a) State distribution plot. (b) Individual sequence plot. 


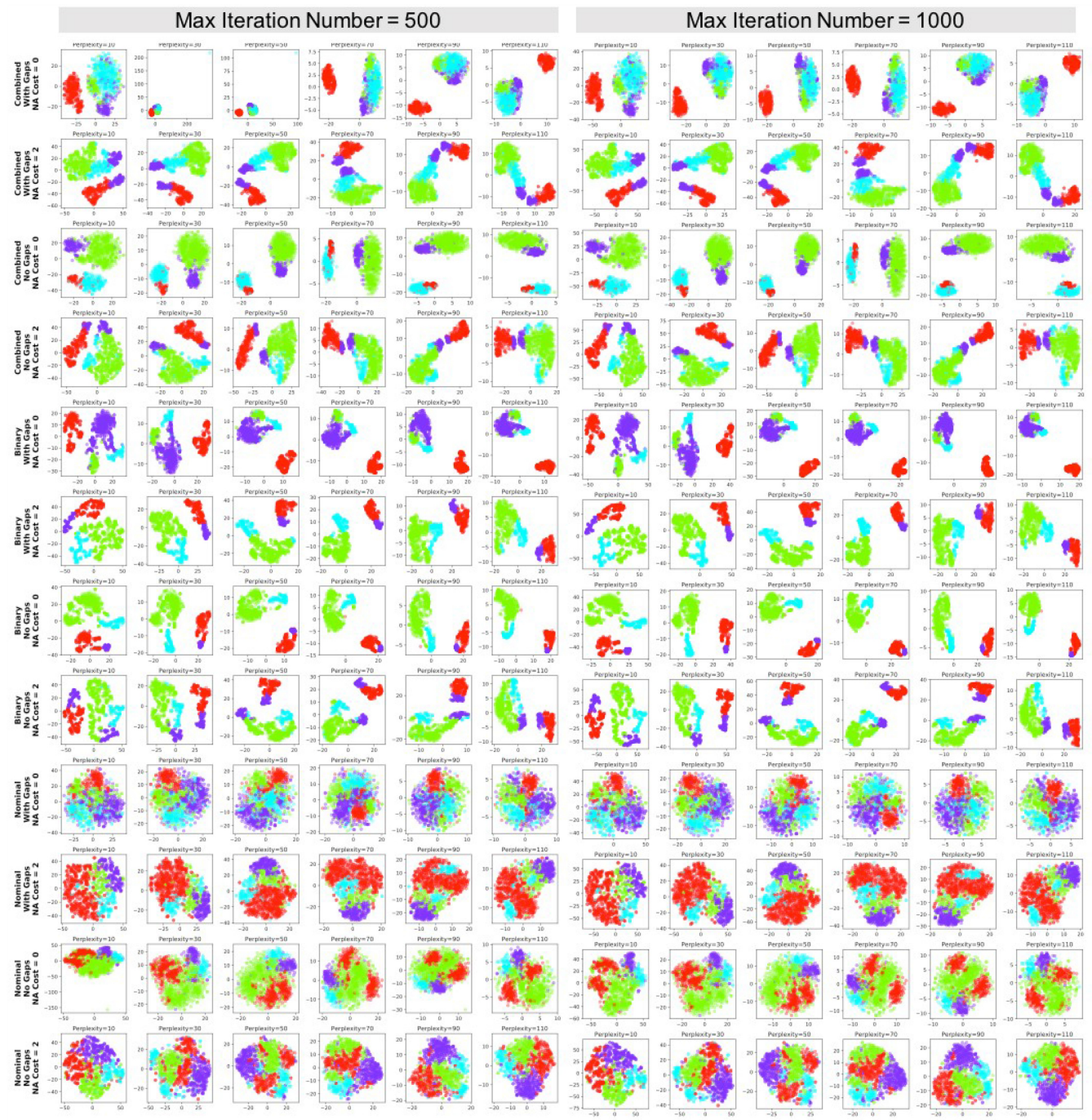

Fig. B.3. t-SNE results from varying perplexity number and maximum iteration number (colored by the clustering solutions). 

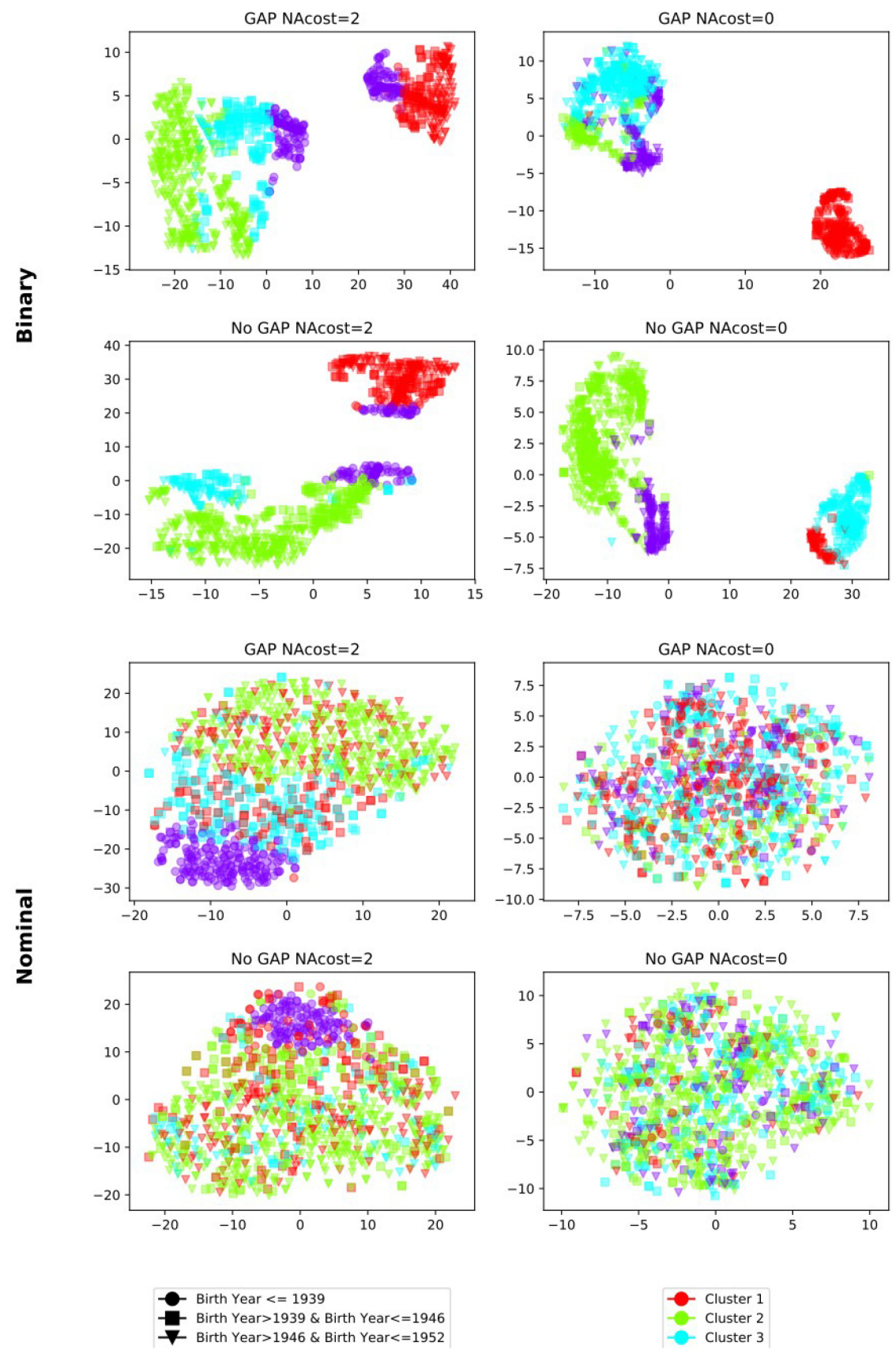

Fig. B.4. Birth year and cluster assignment relationship in binary and nominal domains. 


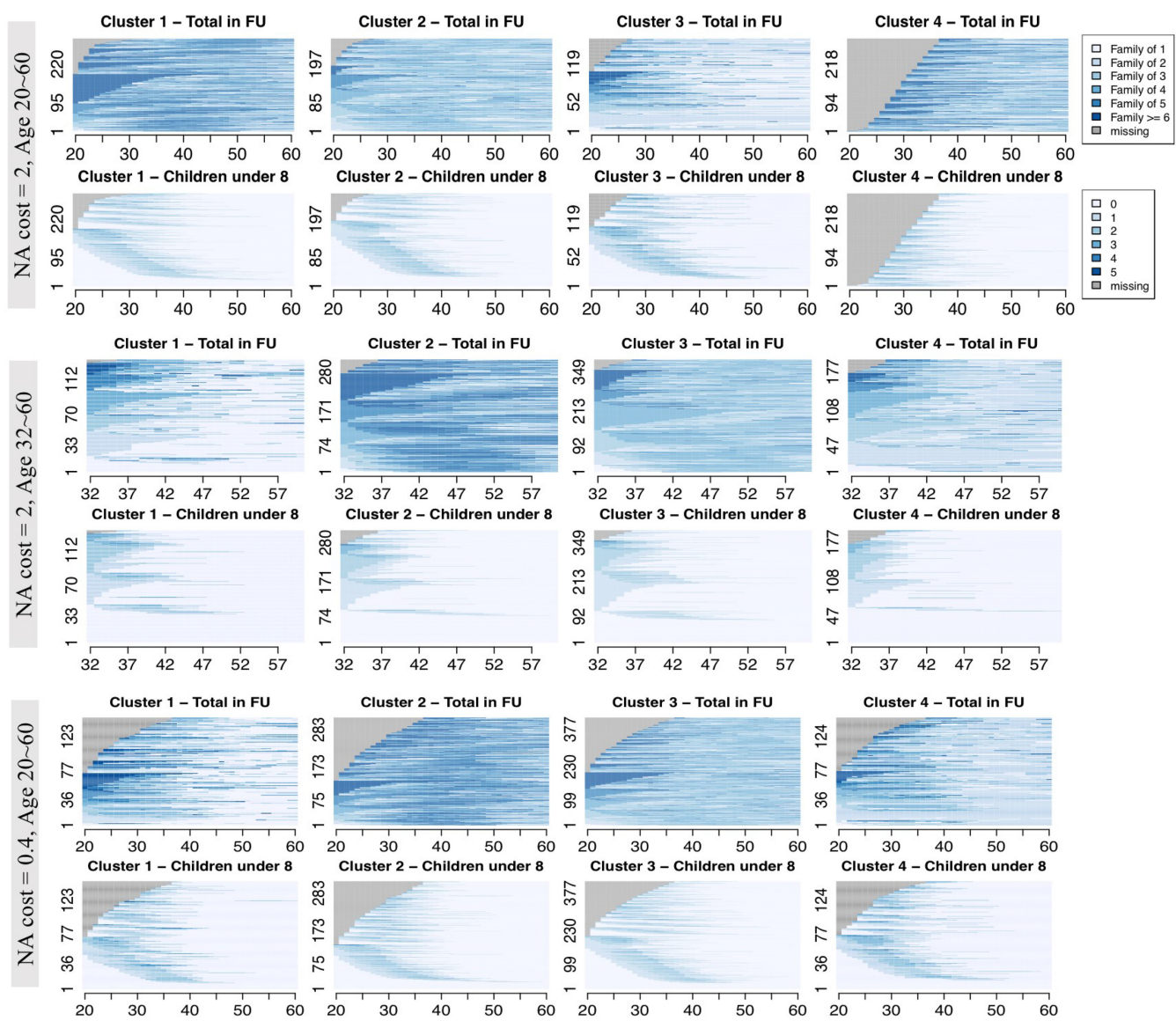

Fig. B.5. Individual sequence plot of the cluster solutions for nominal domain under no survey gap cases. 